\title{
Pericardial Window Procedure
}

National Cancer Institute

\section{Source}

National Cancer Institute. Pericardial Window Procedure. NCI Thesaurus. Code C51618.

A procedure in which an opening is made in the pericardium. 